\title{
FACTORS ASSOCIATED WITH MORTALITY IN EXTRAPULMONARY TUBERCULOSIS PATIENTS AT A TEACHING HOSPITAL IN GHANA
}

\author{
N. NASSIKAS ${ }^{1}$, H. YANG ${ }^{2}$, A. FORSON ${ }^{3,4}$, E. KWARTENG ${ }^{4}$, A. KWARA $^{1}$ \\ ${ }^{1}$ Alpert Medical School of Brown University, Providence, RI, ${ }^{2}$ Department of Biostatistics and Computational \\ Biology, University of Rochester Medical Center, Rochester, NY, ${ }^{3}$ University of Ghana Medical School, Ac- \\ cra, Ghana, ${ }^{4}$ Chest Clinic, Korle-Bu Teaching Hospital, Accra, Ghana
}

DOI: $h$ ttp://dx.doi.org/10.4314/gmj.v49i4.3

Corresponding Author: Dr. Awewura Kwara

Conflict of Interest: None declared

\section{SUMMARY}

Objectives: To investigate the clinical manifestations and factors associated with mortality in patients with extrapulmonary tuberculosis (EPTB) at the Korle-Bu Teaching Hospital Chest Clinic in Accra, Ghana.

Design: We conducted a retrospective chart review of patients treated for EPTB at the Chest Clinic between January 1, 2009 and December 31, 2011. Patients with a new diagnosis of EPTB without concomitant pulmonary disease, aged 18 years or older, and who were treated at the Chest Clinic were eligible for participation in the study. Relevant data were abstracted from medical records and entered into a database. The factors associated with mortality were examined using bivariate and multivariate analysis.

Results: Of the 157 patients in the study, the most affected age group was $25-34$ years old $(33.1 \%), 57.3 \%$ were male, and $71(55.5 \%)$ of the 128 patients tested for HIV were sero-positive. Overall, 62 (39.5\%) died during EPTB treatment. Mortality was associated with disseminated TB (AOR 149.85; $\mathrm{P}<0.001$ ), TB meningitis (AOR 79.14; $\mathrm{P}<0.001$ ), abdominal TB (AOR 23.59; $\mathrm{P}=0.011$ ), pleural effusion ( $\mathrm{AOR} 12.6 ; \mathrm{P}=$ 0.021 ) and age (AOR 1.05; $\mathrm{P}=0.021$ ). Among HIV co-infected patients, early initiation of ART reduced mortality rate.

Conclusions: The site of EPTB was a key determinant of mortality. Given that death occurs soon after diagnosis, patients with suspected TB meningitis, disseminated, abdominal and pleural TB should be targeted for early diagnosis and treatment to reduce the high EPTB mortality in our setting.

Key words: Extrapulmonary TB, HIV coinfection, Treatment outcomes, Mortality, Adults, Ghana
Email: akwara@lifespan.org

\section{INTRODUCTION}

Tuberculosis (TB) is the second leading cause of death due to an infectious disease worldwide. ${ }^{1}$ An estimated 8.6 million new cases of tuberculosis (TB) were diagnosed in 2012 and 1.3 million died as a result of the disease, 0.3 million of whom were HIV positive TB patients. ${ }^{1}$ Despite declining rates of TB incidence and mortality worldwide, the proportion of extrapulmonary tuberculosis (EPTB) cases has increased..$^{2-8}$ Extrapulmonary tuberculosis accounts for more than $20 \%$ of TB cases in the United States and Europe. ${ }^{9}$ Inhalation of Mycobacterium tuberculosis infects the pulmonary system, but can infect any organ system via lympho-hematogenous dissemination., ${ }^{2}$ There are multiple forms of EPTB, including pleural TB and lymphatic TB most commonly, as well as abdominal TB, meningeal TB, skeletal TB, and pericardial TB., ${ }^{3,4}$ 7, 11-13 The lymphatic, and meningeal forms of TB have a higher incidence in non-Caucasians. ${ }^{14}$

Extrapulmonary TB cases have increased more than ten-fold in seven years in Ghana, from 109 new cases reported in 1995 to 1,301 new cases reported in $2012 .{ }^{1}$ It is widely reported that EPTB occurs more frequently in immunocompromised patients. ${ }^{8,15,16}$ EPTB accounts for more than $50 \%$ of tuberculosis cases in HIV/AIDS patients as compared to $15-20 \%$ of TB cases in immunocompetent patients. ${ }^{10,17}$ In fact, EPTB is considered an AIDS defining disease. ${ }^{18} \mathrm{HIV}$ co-infection is associated with more severe forms of EPTB, such as disseminated and meningeal TB, and a higher risk of death. ${ }^{19}$ Studies have shown that patients with EPTB tend to deteriorate more rapidly and have higher mortality rates as compared to patients with pulmonary $\mathrm{TB} .{ }^{4,20}$

In a previous study on outcomes of TB patients, we found that TB meningitis and disseminated disease were significantly associated with death in the multivariate analysis. ${ }^{21}$ 
Given the relatively small proportion of EPTB (37\%) in our previous study, we were not able to adequately assess the risk of death due to other forms of EPTB or the clinical characteristics associated with death.

In this study, we sought to identify the characteristics of patients with EPTB that are associated with increased risk of death. Such data is needed to inform the design of focused strategies to improve the outcome of EPTB among those at highest risk of death.

\section{METHODS}

Patients aged 18 years or older who were newly diagnosed with EPTB at the Korle-Bu Hospital between January 1, 2009 and December 31, 2011 were eligible for participation in the study. Exclusion criteria included age younger than 18 years old, transferring out to other DOTS centers before treatment completion, and concomitant pulmonary TB. WHO guidelines classify patients with concomitant pulmonary TB and EPTB as pulmonary TB (PTB), and consequently these patients were excluded from our study. ${ }^{1}$

Patients receiving Category II treatment, defined as the retreatment of TB patients with first line medications, were also excluded. ${ }^{22}$ Patients who had their treatment interrupted for two consecutive months or more were defined as "lost to follow-up" in accordance with WHO guidelines. ${ }^{1}$ The Institutional Review Boards of Brown University and University of Ghana Medical School for human subjects reviewed and approved this study. We performed a retrospective study using medical records from the Korle-Bu Hospital Chest Clinic. A chart abstraction form was used to collect data such as age, sex, date of presentation and death, clinical features, diagnostic tests performed, sites of EPTB, weight, and height. For HIV-infected patients, information such as the CD4 cell count was abstracted from TB medical records and from Korle-Bu HIV clinic records.

EPTB cases were defined based on the World Health Organization (WHO) criteria. ${ }^{1}$ EPTB patients were identified based their medical charts, which indicated whether the patient had a diagnosis of EPTB or pulmonary TB. A screening HIV test was performed using HIV 1-2 Stat-Pak ${ }^{\circledR}$ (Alere) and if positive, a confirmatory test was performed using OraQuick ${ }^{\circledR}$ ADVANCE Rapid HIV-1/2 antibody test. The Korle-Bu Teaching Hospital in Accra, Ghana, serves as a tertiary referral hospital for the surrounding urban community. Tuberculosis treatment consisted of two months of isoniazid, rifampin, ethambutol and pyrazinamide and four to ten months of isoniazid and rifampin depending on the site of TB infection. Patients with TB meningitis typically receive a 12 months course. The Ghana NTP treatment guidelines modified and published in 2012 recommend 9 to 12 months treatment for neurological disease and pulmonary TB with large cavities, in line with WHO guidelines. ${ }^{23,}{ }^{24}$ In Korle $\mathrm{Bu}$ Teaching Hospital, being a tertiary treatment centre, the NTP policy was extended to include spinal TB, and bone and joint TB for a minimum of 9 or a maximum of 12 months, co-managing with orthopaedic surgeons, who monitored for signs of resolution. All other forms of EPTB were treated for six months.

Patients who died during EPTB treatment were classified as "cases with mortality" and those who survived for the duration of the EPTB treatment were classified as "controls." Mortality was defined as death due to any cause during TB treatment because the cause of death in patients was not recorded in the medical records. Data were entered into a Microsoft Excel database and analysis was performed using STATA software, R, and SAS 9.3. Bivariate analysis of Student's $t$ test and Mann Whitney U test for continuous variables and chi-square test for categorical variables were used to explore the marginal relationship between predictors and death status. Bivariate analysis was used to assess the marginal effect of EPTB sites on outcome.

Reference groups used in bivariate analysis were the condition states as compared to the non-condition states. Multivariate analysis with variable selection was used to assess its conditional marginal effects if EPTB sites were selected. Identification of potential risk factors for all-cause mortality was performed using logistic regression analysis to explore the joint effects of predictors on death status using the subjects' information. The Minimax Concave Penalty (MCP) variable selection method was used to select the predictors that had significant effects on death status. ${ }^{25,26}$ All statistical two-sided tests and comparisons at $\mathrm{P}<0.05$ were considered significant.

\section{RESULTS}

During the study period, 580 patients were diagnosed with EPTB with or without concomitant pulmonary disease. Of these, 164 patients who transferred out to other treatment centers, 39 patients younger than 18 years old, 33 patients who were lost to follow-up, and two Category II patients were all excluded from the study. In addition, 185 patients who had concomitant pulmonary tuberculosis were excluded. The final analysis included 157 patients with EPTB only. Of the 157 patients, the majority of patients $(33.12 \%)$ were $25-34$ years old and $57.32 \%$ were male. 
The common forms of disease included disseminated TB (26.75\%), bone/spine/joint TB (22.93\%) and TB meningitis $(19.11 \%)$

Table 1 Baseline characteristics of 157 patients with extrapulmonary tuberculosis who were treated at the Korle-Bu Teaching Hospital Chest Clinic in Accra, Ghana from 2009-2011

\begin{tabular}{|c|c|c|}
\hline Characteristic & Number & Percent \\
\hline \multicolumn{3}{|l|}{ Age (years) } \\
\hline $18-24$ & 21 & 13.38 \\
\hline $25-34$ & 52 & 33.12 \\
\hline $35-44$ & 36 & 22.93 \\
\hline $45-54$ & 30 & 19.11 \\
\hline $55-65$ & 11 & 7.01 \\
\hline$\geq 65$ & 7 & 4.46 \\
\hline \multicolumn{3}{|l|}{ Gender } \\
\hline Male & 90 & 57.32 \\
\hline Female & 67 & 42.68 \\
\hline \multicolumn{3}{|c|}{ Body Weight $(\mathrm{kg})$ at Start of Treatment } \\
\hline $25-39$ & 14 & 8.92 \\
\hline $40-54$ & 66 & 42.04 \\
\hline$>=55$ & 73 & 46.50 \\
\hline Unknown & 4 & 2.54 \\
\hline \multicolumn{3}{|l|}{ HIV status } \\
\hline Positive & 71 & 45.22 \\
\hline Negative & 57 & 36.31 \\
\hline Unknown & 29 & 18.47 \\
\hline \multicolumn{3}{|c|}{ Site of extrapulmonary tuberculosis } \\
\hline Pleural TB & 11 & 7.01 \\
\hline TB Meningitis & 30 & 19.11 \\
\hline Bone/spine/joint TB & 36 & 22.93 \\
\hline Disseminated TB & 42 & 26.75 \\
\hline Abdominal TB & 8 & 5.10 \\
\hline Lymphatic TB & 18 & 11.46 \\
\hline Pericardial TB & 3 & 1.91 \\
\hline Other & 9 & 5.73 \\
\hline \multicolumn{3}{|l|}{ Treatment Outcome } \\
\hline Completed & 95 & 60.51 \\
\hline Died & 62 & 39.49 \\
\hline
\end{tabular}

Of the 157 patients included in the final analysis, 128 $(81.5 \%)$ had HIV test results available, of whom 71 (55.5\%) were seropositive. Among HIV positive patients, the median CD4 count was 90 cells/microliter (interquartile range (IQR) 25.0 - 241.0). Ten HIV coinfected patients were already on ART a median of 53.5 days (IQR $14.0-108.0$ ) prior to TB. Twelve patients started ART while on TB therapy and 49 never received ART. The median time to ART initiation after starting TB treatment among the twelve patients was 39.5 days (IQR $25.0-66.5$ ).

For patients who completed TB therapy, they completed treatment in a mean of 223.0 days made up of a mean of 9 or 12 months for TB meningitis and bone/joint/spine TB, and 6 months treatment for other forms of EPTB.
The median (IQR) time to death among patients who died during treatment was $6(3.0-25.0)$ days.

\section{Factors associated with treatment outcome}

Overall, 62 patients $(39.49 \%)$ died while receiving EPTB treatment. The demographic and clinical features of the patients who died compared to those who completed therapy are shown in Table 2 .

Table 2 Bivariate analysis of factors associated with death compared to cured or completed therapy

\begin{tabular}{|c|c|c|c|}
\hline Characteristic & Dead $(N=62)$ & Completed (N=95) & P value \\
\hline Median (IQR) age & $39.0(30.0-46.0)$ & $34.0(26.0-48.0)$ & 0.424 \\
\hline \multirow[t]{2}{*}{ Median (IQR) weight } & $50.0(40.0-56.0)$ & $55.4(50.0-69.0)$ & $\begin{array}{l}<0.000 \\
1\end{array}$ \\
\hline & $\mathrm{N}(\%)$ & $\mathrm{N}(\%)$ & \\
\hline Age & & & 0.1044 \\
\hline $18-24$ & $4(19.0)$ & $17(81.0)$ & \\
\hline $25-34$ & $18(34.6)$ & $34(65.4)$ & \\
\hline $35-44$ & $20(55.6)$ & $16(44.4)$ & \\
\hline $45-54$ & $14(46.7)$ & $16(53.3)$ & \\
\hline $55-65$ & $4(36.4)$ & $7(63.6)$ & \\
\hline$\geq 65$ & $2(28.6)$ & $5(71.4)$ & \\
\hline Gender & & & 0.6109 \\
\hline Male & $34(37.8)$ & $56(62.2)$ & \\
\hline Female & $28(41.8)$ & $39(58.2)$ & \\
\hline \multicolumn{4}{|l|}{ Night sweats $^{a}$} \\
\hline Yes & $0(0)$ & $3(100)$ & \\
\hline No & $62(40.3)$ & $92(59.7)$ & \\
\hline Fever & & & 0.1479 \\
\hline Yes & $9(56.2)$ & $7(43.8)$ & \\
\hline No & $53(37.6)$ & $88(62.4)$ & \\
\hline Cough & & & 0.2296 \\
\hline Yes & $9(52.9)$ & $8(47.1)$ & \\
\hline No & $53(37.9)$ & $87(62.1)$ & \\
\hline HIV sero-positive & & & $<0.001$ \\
\hline Yes & $46(64.8)$ & $25(35.2)$ & \\
\hline No & $8(14.0)$ & $49(86.0)$ & \\
\hline Unknown & $8(27.6)$ & $21(72.4)$ & \\
\hline Pleural TB & & & 0.3900 \\
\hline Yes & $3(27.3)$ & $8(72.7)$ & \\
\hline No & $59(40.4)$ & $87(59.6)$ & \\
\hline TB meningitis & & & $<0.001$ \\
\hline Yes & $20(66.7)$ & $10(33.3)$ & \\
\hline No & $42(33.1)$ & $85(66.9)$ & \\
\hline Bone/spine/joint TB & & & $<0.001$ \\
\hline Yes & $2(5.6)$ & $34(94.4)$ & \\
\hline No & $60(49.6)$ & $61(50.4)$ & \\
\hline Disseminated TB & & & $<0.001$ \\
\hline Yes & $33(78.6)$ & $9(21.4)$ & \\
\hline No & $29(25.2)$ & $86(74.8)$ & \\
\hline Lymphatic TB & & & 0.0089 \\
\hline Yes & $2(11.1)$ & $16(88.9)$ & \\
\hline No & $60(43.2)$ & $79(56.8)$ & \\
\hline Abdominal TB & & & 0.3894 \\
\hline Yes & $2(25.0)$ & $6(75.0)$ & \\
\hline No & $60(40.3)$ & $89(59.7)$ & \\
\hline \multicolumn{4}{|l|}{ Pericardial TB ${ }^{a}$} \\
\hline Yes & $0(0.0)$ & $3(100.0)$ & \\
\hline No & $62(40.3)$ & $92(59.7)$ & \\
\hline
\end{tabular}

${ }^{a} \mathrm{P}$-values for night sweat symptom and for pericardial TB infection are not available given the low sample size for these two variables. 
The bivariate analysis revealed that patients who died were more likely to have disseminated TB, TB meningitis, and to have HIV coinfection (Table 2). Those with lymphatic TB and bone/spine/joint TB were less likely to die (Table 2).

In the multivariate model (Table 3), the sites of EPTB associated with death were disseminated TB (adjusted odds ratio (AOR) 149.85, 95\% confidence interval (CI) $19.44->999.99 ; \mathrm{P}<0.001$ ), TB meningitis (AOR 79.14, 95\% CI 11.01 - 568.97; $\mathrm{P}<0.001)$, and $\mathrm{ab}-$ dominal TB (AOR 23.59, 95\% CI 2.05 - 271.54; $\mathrm{P}=$ 0.0282 ). Other characteristics associated with mortality in multivariate analysis included age as a continuous variable in years (AOR 1.05, 95\% CI 1.01-1.09; P = 0.021 ) and pleural effusion (AOR 12.6, 95\% CI $1.46-$ 109.32; $\mathrm{P}=0.021$ ).

Table 3 Multivariate analysis of factors associated with mortality in EPTB patients at a the Korle-Bu Chest Clinic in Ghana

\begin{tabular}{|l|l|l|l|}
\hline Risk factor & Odds ratio & $95 \%$ CI & P value \\
\hline Age & 1.05 & $1.01-1.10$ & 0.021 \\
\hline $\begin{array}{l}\text { HIV sero-negative } \\
\text { versus unknown }\end{array}$ & 0.33 & $0.07-1.58$ & 0.063 \\
\hline $\begin{array}{l}\text { HIV sero-positive } \\
\text { versus unknown }\end{array}$ & 1.03 & $0.24-4.46$ & 0.294 \\
\hline $\begin{array}{l}\text { Pleural Effusion } \\
\text { (Yes vs. No) }\end{array}$ & 12.6 & $1.46-109.32$ & 0.021 \\
\hline $\begin{array}{l}\text { Abdominal (Yes } \\
\text { vs. No) }\end{array}$ & 23.59 & $2.05-271.54$ & 0.011 \\
\hline $\begin{array}{l}\text { TB meningitis } \\
\text { (Yes vs. No) }\end{array}$ & 79.14 & 11.01 & 568.97 \\
\hline $\begin{array}{l}\text { Lymphatic disease } \\
\text { Yes vs. No) }\end{array}$ & 8.96 & $0.86-93.78$ & 0.067 \\
\hline $\begin{array}{l}\text { Disseminated TB } \\
\text { (Yes vs. No) }\end{array}$ & 149.85 & $\begin{array}{l}19.44->001 \\
999.99\end{array}$ & $<0.001$ \\
\hline
\end{tabular}

Patients with TB meningitis and disseminated TB (i.e. disease sites that were associated with high risk of death) compared to those with all other forms of EPTB were more likely to be HIV positive $(77.8 \%$ vs. $17.6 \%$, $\mathrm{P}<0.0001)$. History of cough and fever as well as time between TB diagnosis and HIV testing, and time between TB diagnosis and TB treatment initiation were similar in the two groups $(\mathrm{P}>0.05)$.

Among HIV-infected patients, the mortality rate was highest in patients who never started ART, followed by patients who started ART before EPTB diagnosis and treatment, and lowest in patients who started ART after starting EPTB treatment $(79.2 \%$ vs. $54.5 \%$ vs. $16.7 \%$ respectively; $\mathrm{P}<0.0002)$. In HIV co-infected EPTB patients, sites of EPTB infection associated with an increased risk of death were TB meningitis (AOR 8.0, 95\% CI $1.69-37.95 ; \mathrm{P}=0.0088)$, and disseminated TB (AOR 18.0, 95\% CI $3.84-84.28$; $\mathrm{P}=0.0002$ ).

\section{DISCUSSION}

This study investigated factors associated with mortality in a cohort of patients with EPTB who received treatment at a teaching hospital clinic in Accra, Ghana. Many previous studies on EPTB have focused on characteristics of EPTB patients while few have looked at what predicts death in this population. The current study reports the predictors of mortality in all patients with EPTB as well as in those with HIV coinfection. Increasing age, TB meningitis, as well as disseminated, abdominal, and pleural TB disease were independent factors associated with increased risk of mortality.

The higher risk of death in our study among patients with disseminated $\mathrm{TB}$ and $\mathrm{TB}$ meningitis is consistent with prior studies. ${ }^{4,21,27}$ In our cohort, patients with these severe forms of EPTB were more likely to have HIV coinfection. HIV coinfection likely increased the risk of severe disease and death because of immunosuppression and delay in starting ART. Cases of EPTB, especially the severe forms of EPTB, are more often associated with a delayed diagnosis or are even missed completely and diagnosed at death. ${ }^{7,12,28}$

Age over 40 years old, weight, and immunocompromised states have been associated with mortality and may predispose patients to more serious forms of EPTB. ${ }^{19,27,29-31}$ A high index of clinical suspicion needs to be employed in order to detect EPTB early given that the presentation may be non-specific. ${ }^{12,13,32}$ In our study, death occurred within a median of six days after diagnosis, which underscores the need for early diagnosis and empiric therapy. Patients with lymphatic system, bone, joint, or spine TB were less likely to die likely because of less severe disease or early recognition and therapy.

HIV infection is an important factor associated with increased mortality in TB patients. In our study, 65\% of HIV co-infected EPTB patients died before completing TB treatment, while only $18.6 \%$ of HIV negative EPTB patients died.

Severe forms of EPTB (meningeal and disseminated) were more likely to occur in the HIV-infected patients in our study, which is consistent with previous studies. 3, 4, 19, 29, 30 Low CD4 counts in EPTB patients co-infected with HIV have also been shown to increase risk of disseminated or meningeal forms of TB. ${ }^{19,32}$

HIV patients who never started ART had a higher risk of death compared to those who started ART either before or after starting EPTB treatment, illustrating the consequences of untreated HIV infection on EPTB outcomes. 
Our study showed that nearly four out of five HIVinfected patients with EPTB who never started ART died as compared to one out of every six who started ART after starting EPTB treatment or just over half who started ART before EPTB treatment, illustrating the importance of initiating ART in HIV coinfected patients. Overall, $49(80 \%)$ of the 61 patients who were not on ART at the time of EPTB diagnosis never initiated ART during TB treatment. While we could not evaluate the reasons for the delays in initiating ART in the study patients, all patients should have initiated ART during TB treatment.

The WHO currently recommends that ART be initiated irrespective of CD4 cell count for all people with HIV and active TB. ${ }^{33,34}$ TB treatment should be started first, followed by ART as soon as possible and within the first 8 weeks of starting TB treatment. ${ }^{34}$ The association between older age and increased risk of mortality is most likely because of age-associated immunosuppression and comorbid conditions.

We recognize that our study has several limitations. First, because of costs and high patient numbers, cultures for Mycobacterium tuberculosis are infrequently performed at Korle-Bu. Thus, the diagnosis of EPTB was clinical in most cases and not confirmed. The retrospective nature of the study was associated with missing data including unknown HIV status for 29 patients with ETPB. This could have affected the relationship between death and HIV status. Additionally, the exclusion of patients that were referred out or lost to follow-up makes overstatement of mortality more likely. Our findings may be less generalizable because we only studied patients seen at an urban center teaching hospital and therefore have more severe or complicated disease.

\section{CONCLUSION}

The mortality rate of EPTB in our study population was high and site of disease including TB meningitis and disseminated disease were the main determinants of death. Our data suggest that death occurs early in a majority of the patients at risk of death with EPTB, underscoring the need for rapid diagnosis and treatment in some of these patients. While the site of disease is not modifiable at presentation, early diagnosis and therapy of these severe forms of EPTB will be necessary to reduce mortality. In addition, the early use of ART could impact mortality in patients with HIV coinfection.

\section{ACKNOWLEDGEMENTS}

We are greatly appreciative of the assistance the staff provided at the Korle-Bu Teaching Hospital. We would also like to thank the Alpert Medical School Summer Assistantship Program for funding this research and making this project possible. Dr. Kwara received support from NICHD grant number HD071779. Dr. Yang provided core services through support from the University of Rochester Center for AIDS Research (CFAR), an NIH-funded program (P30 AI078498)

\section{REFERENCES}

1. Organization WH. Global tuberculosis teport 2013: World Health Organization (WHO); 2013 [cited 2013 November 8, 2013]. Available from: http://www.who.int/iris/handle/10665/91355.

2. Elder NC. Extrapulmonary tuberculosis. A review. Arch Fam Med. 1992;1(1):91-8.

3. Peto HM, Pratt RH, Harrington TA, LoBue PA, Armstrong LR. Epidemiology of extrapulmonary tuberculosis in the United States, 1993-2006. Clin Infect Dis. 2009;49(9):1350-7.

4. Kourbatova EV, Leonard MK, Jr., Romero J, Kraft C, del Rio C, Blumberg HM. Risk factors for mortality among patients with extrapulmonary tuberculosis at an academic inner-city hospital in the US. Eur J Epidemiol. 2006;21(9):715-21.

5. Kipp AM, Stout JE, Hamilton CD, Van Rie A. Extrapulmonary tuberculosis, human immunodeficiency virus, and foreign birth in North Carolina, 1993 - 2006. BMC Public Health. 2008;8:107.

6. Garcia-Rodriguez JF, Alvarez-Diaz H, LorenzoGarcia MV, Marino-Callejo A, Fernandez-Rial A, Sesma-Sanchez P. Extrapulmonary tuberculosis: epidemiology and risk factors. Enferm Infecc Microbiol Clin. 2011;29(7):502-9.

7. Sandgren A, Hollo V, van der Werf MJ. Extrapulmonary tuberculosis in the European Union and European Economic Area, 2002 to 2011. Euro Surveill. 2013;18(12).

8. Yang Z, Kong Y, Wilson F, Foxman B, Fowler $\mathrm{AH}$, Marrs CF, et al. Identification of risk factors for extrapulmonary tuberculosis. Clin Infect Dis. 2004;38(2):199-205.

9. Tortoli E, Russo C, Piersimoni C, Mazzola E, Dal Monte P, Pascarella M, et al. Clinical validation of Xpert MTB/RIF for the diagnosis of extrapulmonary tuberculosis. Eur Respir J. 2012;40(2):442-7.

10. Golden MP, Vikram HR. Extrapulmonary tuberculosis: an overview. Am Fam Physician. 2005;72(9):1761-8.

11. Lin CY, Chen TC, Lu PL, Lai CC, Yang YH, Lin WR, et al. Effects of gender and age on development of concurrent extrapulmonary tuberculosis in 
patients with pulmonary tuberculosis: a population based study. PLoS One. 2013;8(5):e63936.

12. Rieder HL, Kelly GD, Bloch AB, Cauthen GM, Snider DE, Jr. Tuberculosis diagnosed at death in the United States. Chest 1991;100(3):678-81.

13. Prakasha SR, Suresh G, D'Sa I P, Shetty SS, Kumar SG. Mapping the pattern and trends of extrapulmonary tuberculosis. $J$ Glob Infect Dis. 2013;5(2):54-9.

14. Mehta JB, Dutt A, Harvill L, Mathews KM. Epidemiology of extrapulmonary tuberculosis. A comparative analysis with pre-AIDS era. Chest. 1991;99(5):1134-8.

15. Gomes T, Vinhas SA, Reis-Santos B, Palaci M, Peres RL, Aguiar PP, et al. Extrapulmonary tuberculosis: Mycobacterium tuberculosis strains and host risk factors in a large urban setting in Brazil. PLoS One. 2013;8(10):e74517.

16. Antony SJ, Harrell V, Christie JD, Adams HG, Rumley RL. Clinical differences between pulmonary and extrapulmonary tuberculosis: a 5-year retrospective study. $J$ Natl Med Assoc. 1995;87(3):187-92.

17. Sharma SK, Mohan A. Extrapulmonary tuberculosis. Indian J Med Res. 2004;120(4):316-53.

18. Naing C, Mak JW, Maung M, Wong SF, Kassim AI. Meta-analysis: the association between HIV infection and extrapulmonary tuberculosis. Lung. 2013;191(1):27-34.

19. Leeds IL, Magee MJ, Kurbatova EV, del Rio C, Blumberg HM, Leonard MK, et al. Site of extrapulmonary tuberculosis is associated with HIV infection. Clin Infect Dis. 2012;55(1):75-81.

20. Lorent N, Sebatunzi O, Mukeshimana G, Van den Ende J, Clerinx J. Incidence and risk factors of serious adverse events during antituberculous treatment in Rwanda: a prospective cohort study. PLoS One. 2011;6(5):e19566.

21. Burton NT, Forson A, Lurie MN, Kudzawu S, Kwarteng E, Kwara A. Factors associated with mortality and default among patients with tuberculosis attending a teaching hospital clinic in Accra, Ghana. Trans $R$ Soc Trop Med Hyg. 2011;105(12):675-82.

22. Organization WH. Global tuberculosis control: WHO report 2011: Geneva : World Health Organization; 2011 [cited 2012 March 15, 2012]. Available from:

http://apps.who.int/iris/handle/10665/44728
23. NTP Working Group. NTP Training Manual, Edition 2. Ghana Health Service, 2012.

24. TB Care I. International Standards for Tuberculosis Care, Edition 3. TB Care I, The Hague. 2014.

25. Breheny P, Huang J. Coordinate Descent Algorithms for Nonconvex Penalized Regression, with Applications to Biological Feature Selection. Ann Appl Stat. 2011;5(1):232-53.

26. Zhang C-H. Nearly unbiased variable selection under minimax concave penalty. The Annals of Statistics. 2010;38(2):894-942.

27. Sevgi DY, Derin O, Alpay AS, Gunduz A, Konuklar AS, Bayraktar B, et al. Extrapulmonary tuberculosis: 7 year-experience of a tertiary center in Istanbul. Eur J Intern Med. 2013;24(8):864-7.

28. Solovic I, Jonsson J, Korzeniewska-Kosela M, Chiotan DI, Pace-Asciak A, Slump E, et al. Challenges in diagnosing extrapulmonary tuberculosis in the European Union, 2011. Euro Surveill. 2013;18(12).

29. Cherian A, Thomas SV. Central nervous system tuberculosis. Afr Health Sci. 2011;11(1):116-27.

30. Ducomble T, Tolksdorf K, Karagiannis I, Hauer B, Brodhun B, Haas W, et al. The burden of extrapulmonary and meningitis tuberculosis: an investigation of national surveillance data, Germany, 2002 to 2009. Euro Surveill. 2013;18(12).

31. Benova L, Fielding K, Greig J, Nyang'wa BT, Casas EC, da Fonseca MS, et al. Association of BMI category change with TB treatment mortality in HIV-positive smear-negative and extrapulmonary TB patients in Myanmar and Zimbabwe. PLoS One. 2012;7(4):e35948.

32. Jaryal A, Raina R, Sarkar M, Sharma A. Manifestations of tuberculosis in HIV/AIDS patients and its relationship with CD4 count. Lung India. 2011;28(4):263-6.

33. Organization WH. Guidelines for treatment of tuberculosis fourth edition: World Health Organization; 2010 [cited 2015 March 2, 2015]. 2010: [Available from: http://www.who.int/tb/publications/2010/9789241 547833/en/.

34. Organization WH. Rapid advice antiretroviral therapy for HIV infection in adults and adolescents: World Health Organization; 2009 [cited 2015 March 2, 2015]. November 2009: [Available from:

http://www.who.int/hiv/pub/arv/rapid advice art.p df. $\bullet$ 